\title{
Anger at US plan to drop physics experiment
}

\section{Geoff Brumfiel, Washington}

Plans to shut down an international highenergy physics experiment have prompted an angry response from the project's foreign partners, some of whom say the decision could endanger future international collaborations with the United States.

The experiment at Brookhaven National Laboratory in New York state, known as E949, is designed to spot very rare types of particle decay. These can be used to measure the weak force that acts between quarks. Only two such decays have been observed, in other experiments, over the past decade. E949 was expected to capture up to 20 more decays in the next two years, but is now likely to end in April.

The Department of Energy (DOE), which funds the Brookhaven laboratory, announced plans to end the project last week after receiving no increase in its budget for the 2003 financial year (see Nature 415, 564; 2002). The money saved will help to finance upgrades to the giant Tevatron accelerator at Fermilab, near Chicago.

The two-thirds of E949's researchers who came from outside the United States seem to have been left in the lurch. "Our group has built tracking devices, high-speed electronics and many other detectors, all in the expectation that this would be carried out as planned," says Doug Bryman, a physicist at the University of British Columbia in Canada and spokesperson for the project.
Shojiro Sugimoto, from the KEK accelerator in Tsukuba, Japan, adds that several $\mathrm{PhD}$ students from Tokyo and Kyoto universities may have to abandon their theses.

Jean-Michel Poutissou, associate director of TRIUMF, Canada's national laboratory for particle and nuclear physics, says that the decision could affect future projects. "I think it will have a major impact on the way we deal with American collaborations," he says. Poutissou points out that E949's Canadian contingent will soon go before a government committee to request funding for the next three years. "How can they make a decision if we don't know the host laboratory will make good on the promises made?" he asks.
US officials acknowledge that the decision had caused difficulties for their partner nations. "It is regrettable," says Jim Decker, the acting director of the Office of Science at the DOE. "We particularly don't like to do this in a situation where researchers from other countries are affected, but sometimes it becomes unavoidable."

But a senior official at the National Science Foundation says he doubts that the decision will damage future international projects, such as the proposed Next Linear Collider. "I don't think it will have a direct impact on other collaborations," he says. "There's a long history of experiments ending before their time."

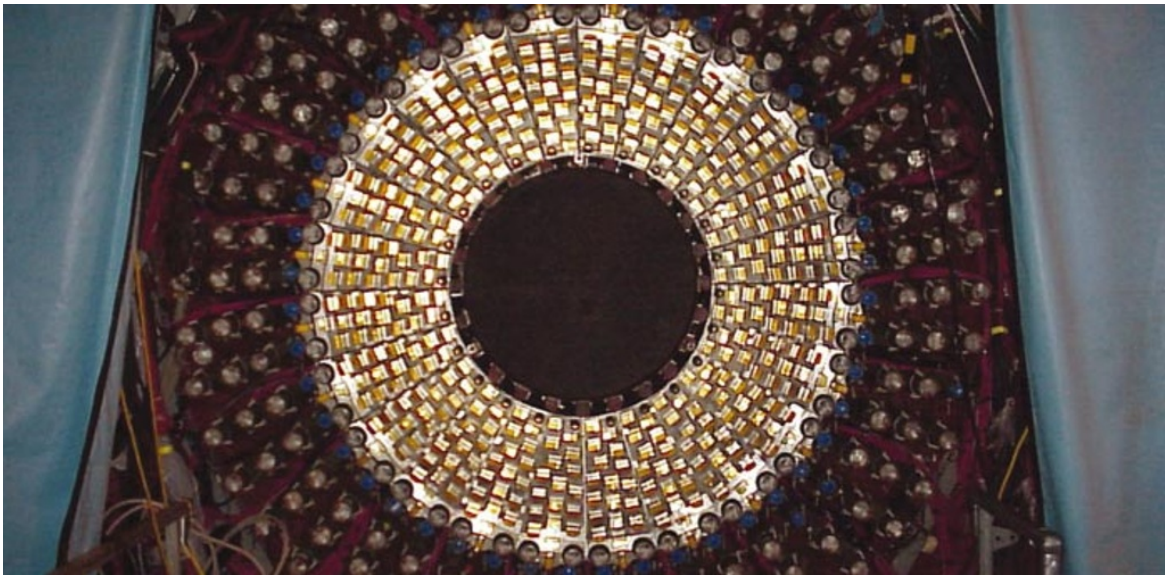

Brookhaven blues: the E949 experiment to detect rare particle decays could end within months.

\section{Researchers fear web information will prompt attacks}

\section{Tony Reichhardt, Washington}

Scientific societies are urging the US Department of Agriculture to give less information on its website about researchers who use laboratory animals.

Robert Rich, president of the Federation of American Societies for Experimental Biology (FASEB), wrote to the department's Animal and Plant Health Inspection Service (APHIS) on 6 February, asking it to revise its procedures on reports by animal-welfare inspectors. These have been posted on the Internet since last October, in accordance with the 1996 Electronic Freedom of Information Act.

Rich warned that some reports include "excessive detail" about researchers, including the addresses of their laboratories, that "may expose individuals to harassment from animal-rights terrorists". He also expressed concern that some information might be inaccurate or preliminary.

Several other groups have joined FASEB in requesting that information allowing the

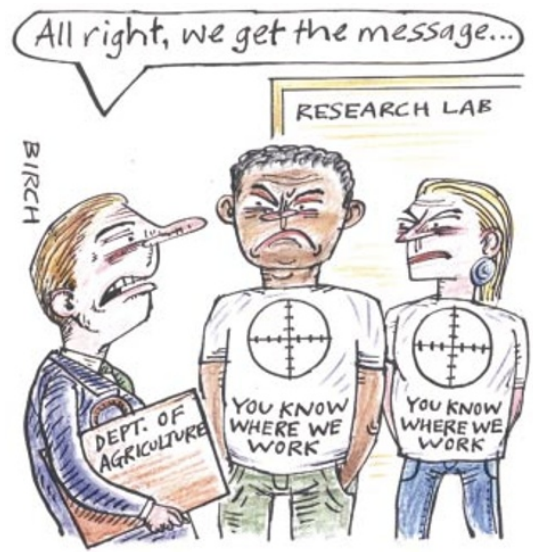

identification of individuals or laboratory locations should not be released.

George Nethercutt (Republican,

Washington), who sits on the House of Representatives agriculture appropriations subcommittee and science committee, has asked APHIS "to work closely with the research community to resolve this matter".
His spokesman, Robert Neal, says that there could be "legislative remedies" if the service does not act voluntarily. "We don't have to make it easy for people who are clearly hostile to research," he says.

Nethercutt was scheduled to testify this week at a congressional hearing on 'ecoterrorism' by the forestry subcommittee of the House Resources Committee, chaired by Scott McInnis (Republican, Colorado).

Groups such as the Earth Liberation Front (ELF) — which claims to have inflicted $\$ 30$ million in property damage against companies and universities it accuses of harming the environment regularly target biotechnologists, according to Neal. The ELF has claimed responsibility for arson (see Nature 411, 509; 2001) and other attacks on biotech facilities.

Nethercutt has proposed legislation that would stiffen the criminal penalties for such activities. It would also give money to the National Science Foundation to study improved security measures. 